\title{
Processo de institucionalização da educação ambiental: tendências, correntes e concepções
}

\author{
Angélica Góis Müller Morales ${ }^{1}$
}

Resumo: A educação ambiental vem se formando numa rede de concepções, por meio de diálogos e disputas de sentidos diante da relação sociedade-natureza. Assim, este artigo teve como objetivo analisar a narrativa da educação ambiental, focando suas tendências e concepções que vem permeando o discurso dos profissionais educadores ambientais. As várias concepções sobre o ambiente propiciam uma diversidade que pode ser enriquecida, em perspectiva sincrônica, pela combinação dos elementos entre as concepções eminentemente complementares que apresentam diversos caminhos, resultados da evolução histórica da própria institucionalização da educação ambiental. Considera-se que a educação ambiental está construindo novas formas de pensar e agir diante das suas múltiplas correntes, as quais têm permeado as discussões do processo formativo da educação ambiental.

Palavras-chave: educação ambiental, concepções, processo formativo.

Abstract: Environmental education is arising from a network of concepts, through intense dialogs and disputes on the meaning of the relationship between society and nature. The present work aimed to analyze the narrative of environmental education, focusing on the main tendencies and concepts which the latest speeches of the environmental educators have been based on. The analysis of environmental concepts reveals that there is a great diversity to be enriched, in synchronous perspective, by the combination of elements through complementary conceptions that present several ways resulted from the historical evolution of environment education's own institutionalization. Environmental education is building several new ways of thinking and acting, responding to a diverse line of discussions that form the environmental education process.

Keywords: environmental education, concepts, formative process.

${ }^{1}$ Docente da Universidade Estadual de Ponta Grossa, Depto. de Biologia Geral (DEBIO/UEPG-PR). Secretária Executiva da Rede de Educação Ambiental do Paraná (REA-PR). Contatos: Rua Delegado Naby Paraná, 241, casa 10, Capão Raso - Curitiba-PR - CEP 81110-120 ou angelicagoismorales@ig.com.br 


\section{Introdução}

É por meio do processo de formação e (re)formação que a sociedade, inserida em contextos históricos e culturais de sua época, cria sentidos que refletem sua maneira de conceber o mundo. Por sua vez, o processo formativo da educação ambiental, comportando uma historicidade, também é formado e reformado dentro de um movimento histórico de diálogos e disputas diante da manifestação da humanidade e, por consequência, de produção de pensamentos significativos sobre a relação da sociedade com a natureza, relatando vários e possíveis caminhos epistemológicos.

Este artigo, de abordagem crítico-reflexiva, apresenta alguns questionamentos iniciais, como: quais os caminhos que a educação ambiental percorre? Quais são as bases de pensamento da educação ambiental?

Tais problematizações implicam analisar as referências do debate da narrativa da educação ambiental e refletir sobre as múltiplas concepções que compõem esse universo multirreferencial, o qual influencia o pensar e o agir dos profissionais educadores ambientais que estão passando por cursos de formação em várias instâncias.

\section{O processo formativo da Educação Ambiental}

A educação ambiental, precedida pelos movimentos ambientalistas, surge no intuito de (re)discutir a relação naturezasociedade, o que denuncia uma crise de conhecimento, política e educativa, a qual, por sua vez, implica a busca de um novo saber ambiental. Neste texto, concorda-se com Leff (2001), que utiliza a expressão saber ambiental para a emergência da construção de um novo saber que ressignifique as concepções do progresso atual para conformar uma nova racionalidade ambiental, por meio do campo da produção do conhecimento, da política e das práticas educativas. Sob esse prisma, o saber ambiental

problematiza o conhecimento fragmentado em disciplinas e a administração setorial do desenvolvimento, para construir um campo 
de conhecimentos teóricos e práticos orientado para a rearticulação das relações sociedade-natureza. Esse conhecimento não se esgota na extensão dos paradigmas da ecologia para compreender a dinâmica dos processos socioambientais [...] O saber ambiental emerge do espaço de exclusão gerado no desenvolvimento das ciências, centradas em seus objetos de conhecimento, e que produz o desconhecimento de processos complexos que escapam à explicação dessas disciplinas (LEFF, 2001, p. 145).

Assim, foi em virtude do repensar a relação sociedade-natureza e da necessidade de intervenção política e cultural que as primeiras iniciativas de educação ambiental se desencadearam, como componente educativo essencial na tentativa de deflagrar ação consciente, crítica e transformadora das posturas em relação ao modo de conceber o ambiente, o mundo e seus semelhantes, assinalando possível articulação entre as ciências naturais e as ciências humanas e sociais. Perante essa articulação, Grün (1996, p. 21) afirma a

necessidade de se adicionar o predicado ambiental à educação. A educação ambiental surge hoje como uma necessidade quase inquestionável pelo simples fato de que não existe ambiente na educação moderna. Tudo se passa como se fôssemos educados e educássemos fora do ambiente.

Grün ainda complementa ressaltando que a "educação deveria ser capaz de reorientar as premissas do agir humano em sua relação com o meio ambiente" (GRÜN, 1996, p. 19). Para o autor, “a educação, então, deveria responder a esse quadro de perplexidade educando os cidadãos para o meio ambiente. Assim, firmou-se hoje uma forte convicção no meio acadêmico-científico e político de que precisamos de uma educação ambiental" (GRÜN, 1996, p. 20).

No mesmo sentido de Grün, Brugger questiona a incorporação ambiental que pressupõe "a aceitação de que a educação não tem sido ambiental” (BRUGGER, 1994, p. 34). Assim, a educação tradicional é totalmente não ambiental, e a educação ambiental parece surgir como 
um complemento ou alternativa para pensar essa educação, que tem caráter acumulativo e concepção estática do conhecimento.

A educação ambiental situa-se na confluência dos campos ambiental e educativo, porém, não emergiu das teorias educacionais, $\mathrm{o}$ que implica estar mais relacionada "aos movimentos ecológicos e ao debate ambientalista do que propriamente ao campo educacional e à teoria da educação" (CARVALHO, 2001, p. 46). É da tradição ambiental, das heranças e perspectivas culturais e da força criadora que animam o campo da educação ambiental que provém a maior parte dos valores éticos e políticos.

Observa-se que a educação incorpora o adjetivo "ambiental", assinalando educação para o meio ambiente; e a educação ambiental irrompe como resposta à problemática ambiental, que busca formar educadores e educadoras que levem em conta a diversidade de olhares sobre o mundo, na tentativa de reintegrar sociedade, natureza, aceitação, reconhecimento e valorização da diversidade cultural.

No entanto, prenuncia-se que a educação ambiental não deve ser idealizada como única "panaceia salvacionista" para a resolução de problemas, mas como uma das possíveis vias para a construção de uma sociedade mais crítica e reflexiva. Por isso, concorda-se com Sato quando esta afirma que educação que não seja ambiental não pode ser chamada de educação. Para essa autora, a educação ambiental é:

um substantivo composto, indissociável em sua essência ontoepistemológica, com dimensões não somente naturais, mas igualmente culturais. Valorizar a identidade da educação ambiental é, portanto, reconhecer que as duas dimensões são intrinsecamente conectadas e interdependentes, tornando os campos epistêmicos fortalecidos pelas lutas ambientalistas e movimentos sociais (SATO, 2001, p. 4).

Embora a verdadeira educação seja ambiental por excelência, uma vez que o planeta não é a somatória de indivíduos isolados em redomas, a educação começou a se tornar ambiental a partir de publicações, conferências, encontros, simpósios, reuniões e 
movimentos realizados ao longo do processo histórico, construindo as premissas que fundamentam a educação ambiental e que são amplamente utilizadas pelos profissionais educadores ambientais.

Historicamente, a expressão educação ambiental (environmental education) foi utilizada pela primeira vez no evento de educação The Keele Conference on Education and the Countryside, promovido pela Universidade de Keele, na Grã-Bretanha, no ano de $1965^{2}$. No evento em questão, a concepção de educação ambiental estava interligada aos princípios básicos da ecologia e de conservação, revelando indícios de confusão com o ensino de Ecologia.

A educação ambiental apresenta uma narrativa marcada por influências de várias visões e concepções, como se pode destacar nas grandes conferências internacionais de Estocolmo (1972), Belgrado (1975), Tbilisi (1977), Moscou (1987), Rio de Janeiro (1992) e Tessalônica (1997), que assinalam o movimento de origem e de legitimidade da educação ambiental tanto para o público interno como para o externo, conforme aponta Carvalho (2001).

Entretanto, não se pretende aqui abordar essas conferências internacionais, mas ressaltar que esses eventos influenciam a institucionalização da educação ambiental no contexto brasileiro, bem como delimitam a diversidade de discursos e práticas que demarcam diferentes tendências e concepções da educação ambiental, implicando a conduta de muitos profissionais educadores ambientais, como se nota nos estudos sobre formação ambiental de Morales (2009), Tozoni-Reis (2004) e Tristão (2004).

As implicações da educação ambiental para o contexto mundial

A educação ambiental, no contexto mundial, afirma e reafirma a necessidade de se considerarem as diversas dimensões do

2 Vale destacar que, segundo Caride (1999, p. 47) e Disinger (1983, apud SUREDA; COLOM, 1989, p. 47), a expressão educação ambiental foi cunhada por Thomas Pritchard, por ocasião da fundação da então denominada União Internacional para a Proteção da Natureza. 
conhecimento e se tornar visível a abordagem interdisciplinar e sistêmica que impera nesse novo saber ambiental.

No entanto, ao se analisarem esses documentos decorrentes dos eventos em destaque no cenário da educação ambiental mundial, é perceptível que o discurso da educação ambiental, com a sua institucionalização, acompanha uma tendência conservadora. Dessa forma, a educação ambiental se apresenta dentro de um discurso superficial e ingênuo, que vem ao encontro do discurso dos segmentos dominantes e hegemônicos.

Segundo Guimarães (2000), existe intencionalidade das classes dominantes em tornar hegemônica a visão da educação e, consequentemente, fazer da educação ambiental um projeto positivo para todos os que se conformam com o sistema neoliberal. Desenvolve-se assim uma visão homogênea sobre a educação ambiental, trazendo-a como resposta à crise ambiental e como vínculo linear entre educação e desenvolvimento.

É notável que são mais privilegiadas as expectativas políticas e econômicas dos países desenvolvidos do que propriamente a práxis direcionada à possível mudança na relação ser humano-naturezasociedade. Apresenta-se, nesse debate ambiental, um senso comum pouco reflexivo e muito generalizado, compatível, muitas vezes, com a economia do mercado.

São nítidos os diversos conflitos entre os países desenvolvidos e subdesenvolvidos por não questionarem o problema dos níveis desiguais de desenvolvimento e a relação com as diversidades culturais, sociais, econômicas, naturais e históricas de dominação existente entre os variados países. Essas tensões estão presentes, principalmente, na discussão da educação ambiental frente ao desenvolvimento sustentável, contradizendo, muitas vezes, o próprio intuito da educação ambiental, que não tem a pretensão de nivelar as diferenças nem, muito menos, as divergências, pois leva em consideração toda a diversidade.

Os documentos da ONU oferecem uma ampla lista de recomendações, mas arraigada de leitura superficial, de discurso 
identificado como formalismo idealizado ${ }^{3}$ e imperativo, e expressam redação camuflada de conflitos e interesses não raro alheios às próprias dinâmicas do campo educativo-ambiental (MEIRA, 2005).

Embora muitos desses documentos tenham cunhado os primeiros pressupostos teóricos da educação ambiental, observa-se que foram elaborados em presença de tensão de negociação entre diferentes representantes (governamentais, não governamentais, instituições privadas, etc.) com interesses variados.

$\mathrm{E}$, por tal conjuntura, nesses discursos oficiais, as visões antropocêntrica e naturalista ainda são predominantes, sendo observadas em muitas das práticas e das atividades de educação ambiental. Isso ocorre porque, na maior parte dos documentos respectivos aos eventos mundiais, as questões ambientais encontram-se restringidas à problemática da poluição da água, do ar, bem como ao exacerbado uso inadequado dos recursos não renováveis ${ }^{4}$, sendo esses considerados problemas naturais e prioritários que trazem riscos à vida humana.

\section{Emergência da educação ambiental brasileira: tendências, correntes e concep̧̧ões}

Sob esses reflexos do cenário mundial, a educação ambiental, no Brasil, emerge na década de 1980 com a crescente institucionalização no cenário das políticas públicas, podendo ser destacadas: a Lei Federal n. 6.938/81, que estabelece a Política Nacional do Meio Ambiente, em que a educação ambiental é situada como um dos componentes que contribuem para a solução dos problemas ambientais e ofertada em todos os níveis de ensino (EA formal) e na comunidade (EA não formal), consolidando a política ambiental do País e a Constituição Federal de 1988, que destaca, no Artigo 225, capítulo VI, o meio

3 Expressão utilizada por Mello (2002) em seu trabalho de dissertação, no qual tece reflexões e análises sobre o formalismo na educação ambiental frente aos documentos internacionais e nacionais. Como a autora evidencia, o formalismo idealizado na educação ambiental consiste no caráter ideal e fantasioso de recomendação oficial, que, muitas vezes, se encontra distante da realidade.

4 Essa restrição representa ainda a redução do ambiente, como conseqência das ciências naturais, em que o embate da educação ambiental centrou-se inicialmente de forma predominante. 
ambiente, abordando a promoção da educação ambiental em todos os níveis de ensino e a conscientização pública para a preservação do meio ambiente.

No caminhar do fortalecimento da educação ambiental no cenário brasileiro, foram criadas as Redes de Educação Ambiental no intuito de integrar e articular instituições e pessoas para que formem elos regionais e locais na difusão e na discussão da temática, por meio de encontros, oficinas e divulgação da informação ambiental, como a Rede Brasileira de Educação Ambiental (REBEA), Rede Paulista de Educação Ambiental (REPEA), Rede de Educação Ambiental da Região Sul (REASul), Rede de Educação Ambiental do Paraná (REAPR), entre outras.

Em decorrência dos compromissos assumidos na Conferência Internacional da Rio-92 e da Constituição Federal de 1988, no ano de 1994, foi inspirado o Programa Nacional de Educação Ambiental (PRONEA), elaborado em conjunto com o Ministério de Meio Ambiente (MMA) e o Ministério de Educação e Cultura (MEC). O PRONEA caracterizou-se como um dos avanços significativos na institucionalização da educação ambiental no País, na perspectiva de aprofundamento e sistematização, bem como de nova visão da relação ser humano-natureza, ao evidenciar a compreensão integrada do meio ambiente.

Com a publicação da Política Nacional de Educação Ambiental, Lei n. 9795/99, a educação ambiental é impulsionada ainda mais no Brasil. São entendidos como educação ambiental os processos por meio dos quais o indivíduo e a coletividade estabelecem valores sociais, conhecimentos, habilidades, atitudes e competências voltadas à preservação e à conservação do meio ambiente, o que reafirma um caráter interdisciplinar, sistêmico e integrador (BRASIL, 1999).

Apenas em 2002 há a regulamentação da Lei n. 9795/99 e do Órgão Gestor da Política Nacional de Educação Ambiental, que definem as bases para a sua execução. Nesse tocante, fica explícito que a educação ambiental é ainda muito inconsistente no ambiente político, dependendo dos interesses de cada representante político e partidário vigente no âmbito nacional. 
Destarte, percebe-se que, ao se tratar da institucionalização da educação ambiental no Brasil, se supõe o entendimento da dinâmica ao longo do tempo, remetendo a cruzamento de um feixe de discursos e ações que, gradualmente, se constitui em uma área de saber particular. Assim, por meio de programas institucionais, políticas públicas, conferências, organizações governamentais e não governamentais, grupos civis e empresariais é que se configura o processo formativo da educação ambiental. Porém, muitas vezes esse processo torna-se conflitante e é realizado de modo descontínuo, contraditório e precário.

A constituição da educação ambiental em suas origens se encontra subordinada ao modelo das ciências da natureza, em que os componentes ecológicos e biológicos se impõem a outros componentes do meio ambiente, porque os discursos iniciais estiveram atrelados à proteção da natureza, direcionando-se com maior frequência à contemplação da natureza do que à interação com a natureza. (GONZÁLEZ GAUDIANO, 1997, p. 59; LOUREIRO, 2006, p. 47).

Contudo, as concepções mudam de acordo com o processo de construção e reconstrução da educação ambiental, já que esse é um campo constante de expansão e reformulações, transformando-se em consonância com a problematização da própria percepção de meio ambiente.

Assim, vale evidenciar os trabalhos de Sauvé (1997) e Sato (2001), que identificaram concepções paradigmáticas sobre o ambiente que, com o desenvolvimento das pesquisas, são ampliadas, conforme pode ser visualizado no Quadro 1.

O quadro apresenta a síntese das concepções do ambiente, as quais estão em constante diálogo entre si, não se prendendo em agrupamentos fechados e classificação imediata. Percebe-se também que as mesmas se encontram relacionadas às estratégias e aos objetivos da própria educação ambiental.

Esse processo de conhecer as diferentes concepções relacionadas ao conceito de meio ambiente, por sua vez, pode expressar práticas pedagógicas e discursos antagônicos e/ou complementares de educadores e educadoras ambientais, como também podem determinar 


\section{as concepções e os caminhos da pesquisa em educação ambiental, que se aproximam, ou seja, são solidárias, a uma epistemologia ambiental.}

\section{Quadro 1 - Concepções sobre o ambiente na educação ambiental.}

\begin{tabular}{|c|c|c|c|c|}
\hline $\begin{array}{c}\text { Representação do } \\
\text { ambiente }\end{array}$ & Palavras-chave & $\begin{array}{c}\text { Problema } \\
\text { identificado }\end{array}$ & Objetivos da EA & Metodologias \\
\hline $\begin{array}{l}\text { Natureza: para ser } \\
\text { apreciada e preservada. }\end{array}$ & $\begin{array}{l}\text { Preservação, árvores, } \\
\text { animais, natureza. }\end{array}$ & $\begin{array}{l}\text { Dicotomia da } \\
\text { relação ser humano- } \\
\text { natureza. }\end{array}$ & $\begin{array}{l}\text { Renovação do ser } \\
\text { humano com a natureza, } \\
\text { tornando-o parte dela; } \\
\text { desenvolvimento da } \\
\text { sensibilidade para o } \\
\text { pertencimento. }\end{array}$ & $\begin{array}{l}\text { - exibições; } \\
\text { • imersão na natureza: } \\
\text { processos de admiração } \\
\text { do meio natural. }\end{array}$ \\
\hline $\begin{array}{l}\text { Recurso: para ser } \\
\text { gerenciado. }\end{array}$ & $\begin{array}{l}\text { Água, resíduos } \\
\text { sólidos, energia, } \\
\text { biodiversidade, ar. }\end{array}$ & $\begin{array}{l}\text { Ser humano } \\
\text { apropriando-se de } \\
\text { forma ilimitada dos } \\
\text { recursos. }\end{array}$ & $\begin{array}{l}\text { Manejo e gestão } \\
\text { ambiental para um futuro } \\
\text { sustentável. }\end{array}$ & $\begin{array}{l}\text { - campanhas de } \\
\text { reciclagem do lixo, entre } \\
\text { outras; } \\
\text { - auditorias. }\end{array}$ \\
\hline $\begin{array}{l}\text { Problema: para ser } \\
\text { resolvido. }\end{array}$ & $\begin{array}{l}\text { Contaminação, efeito } \\
\text { estufa, queimadas, } \\
\text { danos ambientais, } \\
\text { industrialismo. }\end{array}$ & $\begin{array}{l}\text { Relação negativa do } \\
\text { ser humano com o } \\
\text { ambiente ameaçado. }\end{array}$ & $\begin{array}{l}\text { Desenvolver } \\
\text { competências e ações para } \\
\text { a resolução dos } \\
\text { problemas por meio de } \\
\text { comportamentos } \\
\text { responsáveis. }\end{array}$ & $\begin{array}{l}\text { • resolução de problemas; } \\
\text { - intervenção pelo } \\
\text { modelo econômico. }\end{array}$ \\
\hline $\begin{array}{l}\text { Sistema: para } \\
\text { compreensão e tomada } \\
\text { de decisão. }\end{array}$ & $\begin{array}{l}\text { Ecossistema, } \\
\text { desequilíbrio, relações } \\
\text { ecológicas. }\end{array}$ & $\begin{array}{l}\text { Ser humano percebe } \\
\text { o sistema } \\
\text { fragmentado. }\end{array}$ & $\begin{array}{l}\text { Desenvolver pensamento } \\
\text { sistêmi-co para a tomada } \\
\text { de decisão. }\end{array}$ & $\begin{array}{l}\text { - análise das situações; } \\
\text { - modelagem. }\end{array}$ \\
\hline $\begin{array}{l}\text { Meio de vida: para } \\
\text { conhecer e cuidar do } \\
\text { ambiente. }\end{array}$ & $\begin{array}{l}\text { Tudo o que nos } \\
\text { rodeia. }\end{array}$ & $\begin{array}{l}\text { Ser humano é } \\
\text { habitante do } \\
\text { ambiente, porém, } \\
\text { sem o sentido de } \\
\text { pertencimento. }\end{array}$ & $\begin{array}{l}\text { (Re)descobrir os próprios } \\
\text { meios de vida, } \\
\text { despertando o sentido de } \\
\text { pertencimento. }\end{array}$ & $\begin{array}{l}\text { - projetos de jardinagem; } \\
\text { - trilhas interpretativas e } \\
\text { de percepção. }\end{array}$ \\
\hline $\begin{array}{l}\text { Biosfera: como local } \\
\text { para ser vivido. }\end{array}$ & $\begin{array}{l}\text { Planeta Terra, } \\
\text { ambiente global, } \\
\text { visão sistêmica. }\end{array}$ & $\begin{array}{l}\text { Ser humano não é } \\
\text { solidário e a cultura } \\
\text { ocidental não } \\
\text { reconhece a relação } \\
\text { do ser humano com } \\
\text { a Terra. }\end{array}$ & $\begin{array}{l}\text { Desenvolver uma visão } \\
\text { global do ambiente, } \\
\text { considerando as inter- } \\
\text { relações. }\end{array}$ & $\begin{array}{l}\text { - estudos de caso com } \\
\text { problemas globais; } \\
\text { • valorização das } \\
\text { narrativas: histó-rias com } \\
\text { diferentes cosmologias. }\end{array}$ \\
\hline $\begin{array}{l}\text { Projeto comunitário: para } \\
\text { ser envolvido e } \\
\text { comprometido. }\end{array}$ & $\begin{array}{l}\text { Responsabilidade, } \\
\text { projeto político, } \\
\text { transformações, } \\
\text { emancipação, saber } \\
\text { tradicional, } \\
\text { sustentabilidade } \\
\end{array}$ & $\begin{array}{l}\text { Ser humano é } \\
\text { individualista e falta } \\
\text { compromisso com a } \\
\text { comunidade. }\end{array}$ & $\begin{array}{l}\text { Desenvolver a práxis } \\
\text { (ação-reflexão-ação) por } \\
\text { meio do espírito crítico e } \\
\text { coletivo. }\end{array}$ & $\begin{array}{l}\text { - pesquisa-ação } \\
\text { participativa para a } \\
\text { transformação } \\
\text { comunitária; } \\
\text { - fórum com a } \\
\text { comunidade. } \\
\end{array}$ \\
\hline $\begin{array}{l}\text { Relação sociedade-natureża } \\
\text { (concepção emergente e } \\
\text { recorrente nos fundamentos } \\
d a \mathrm{EA} \text { ) }\end{array}$ & $\begin{array}{l}\text { Meio ambiente, } \\
\text { desenvolvimento, } \\
\text { socioambientalismo, } \\
\text { saber ambiental, ética } \\
\text { ambiental. }\end{array}$ & $\begin{array}{l}\text { Ser humano se } \\
\text { depara com } \\
\text { conhecimento } \\
\text { científico } \\
\text { fragmentado e } \\
\text { estilos de vida que } \\
\text { levam ao consumo } \\
\text { exagerado. }\end{array}$ & $\begin{array}{l}\text { Integrar os } \\
\text { conhecimentos sobre } \\
\text { natureza e sociedade, } \\
\text { facilitar a reflexão crítica e } \\
\text { o planejamento ambiental }\end{array}$ & $\begin{array}{l}\text { - interdisciplinaridade; } \\
\text { - diálogo de saberes; } \\
\text { - pedagogia da } \\
\text { complexidade. }\end{array}$ \\
\hline
\end{tabular}


Essas concepções estão relacionadas a um movimento evolutivo e dinâmico no processo de discussões e institucionalização da educação ambiental, já que se concorda que a "educação ambiental se posiciona face ao conceito de meio ambiente como realidade passível de diversas leituras", tornando-se fundamental "considerar a historicidade das questões ambientais” (CARVALHO, 2004, p. 180).

Assim, as concepções de meio ambiente perpassam o pensamento e a ação ora naturalistas, ora antropocêntricos, e ainda, ora sistêmicos, enraizados na relação sociedade-natureza, na qual são inúmeros os problemas identificados a partir dessa dicotomia presente na história da nossa sociedade.

Essas concepções sobre o ambiente podem ser enriquecidas, em perspectiva sincrônica, pela combinação dos elementos entre as concepções eminentemente complementares. Assim, podem ser combinadas em diversos caminhos, bem como enfocadas diacronicamente, porque são resultados da evolução da história.

Como se observa, ao longo do processo formativo da educação ambiental, foram construídos e estabelecidos alguns parâmetros, indicadores, referências e tendências de diferentes concepções, que se agruparam e se aproximaram mais da relação sociedade-natureza de forma solidária e partidária de pensamento complexo. Porém, também há tendências que se centram mais na tradição positivista, partidária de pensamento ainda simplificador, o que permite entender por que certos pressupostos teóricos validam determinadas concepções do processo educativo-ambiental e outros negam.

Entre as concepções da educação ambiental na tendência mais tradicional, destacam-se as categorias relacionadas aos aspectos conservacionista, naturalista e resolutivo, as quais são marcadas por um método empírico-analítico, baseado no objetivismo e no interesse técnico-instrumental.

Nessa concepção conservadora, a educação ambiental foi caracterizada, inicialmente, por enfocar a exaltação da beleza da natureza e centrar-se na categoria naturalista, por meio de aspectos afetivos, experienciais ou espirituais; posteriormente, por meio do debate sobre a degradação ambiental e do caos, emergiram respostas 
conservacionistas a respeito dos recursos naturais, dando ênfase ao processo de gestão ambiental. Percebe-se que essas caracterizações estão em constante dinâmica com o movimento ambientalista, cuja trajetória também foi predominantemente marcada pelas tendências conservacionistas e preservacionistas.

Porém, vale evidenciar as correntes de pensamento que apresentam discussão e problematização mais ampla entre sociedade e natureza, que se aproximam de uma epistemologia ambiental e podem coexistir no mesmo processo de educação ambiental.

Entre as correntes que são mais solidárias e abertas a novos diálogos de saberes, destaca-se a corrente crítico-reflexiva, que traz uma abordagem crítica, emancipatória e práxica, marcada pelo pensamento de Paulo Freire e pelos princípios da Teoria Crítica.

Essa corrente, embasada no pensamento de Paulo Freire, está centrada na aprendizagem, na ação pela ação e para a ação, estando a reflexão integrada nesse processo, o que forma a unidade ação-reflexãoação. Essa práxis, que é atividade social transformadora, implica a ação e a reflexão dos seres humanos sobre o mundo para transformá-lo (FREIRE, 1997, p. 58).

Assim, tem-se uma tendência da Pedagogia Progressista Libertadora, com uma concepção histórico-cultural, inspirada em Paulo Freire, que trouxe a discussão para o campo pedagógico, em que a educação assume caráter amplo no processo de conscientização. Devese refletir sobre o ser humano e seu meio, o que implica que esse ser humano se constrói sobre sua integração, refletindo sobre a realidade, comprometendo-se e compreendendo-se como sujeito histórico de sua própria história.

Percebe-se que o pensamento de Freire não estava centrado na questão ambiental propriamente dita, pois a ele interessava mais os aspectos cognitivos e políticos, pautados na relação dialógica entre o fazer e o aprender, de um lado, e o aprender e o transformar, de outro. No entanto, esse conceito central sobre educação é importante na concepção de educação ambiental em uma vertente transformadora e emancipatória, uma vez que "conhecer, agir e perceber no ambiente deixa de ser um ato teórico-cognitivo e torna-se um processo que se 
inicia nas impressões genéricas e intuitivas e que se vai tornando complexo e concreto na práxis" (LOUREIRO, 2004, p. 130).

Essas concepções assinalam o pensamento freireano como referência para os profissionais educadores ambientais de todas as matrizes inseridas na discussão que permeia a teoria crítica.

Associados à práxis, têm-se os princípios da Teoria Crítica, que estão na discussão da educação ambiental contemporânea, centrada na análise das dinâmicas sociais da problemática ambiental.

Essa teoria foi inicialmente desenvolvida nas ciências sociais, associada à escola de Frankfurt ${ }^{5}$, e analisa um comportamento crítico nos confrontos com a ciência e a cultura, apresentando proposta política de reorganização e transformação da sociedade de modo a superar a crise da racionalidade instrumental.

Por teoria crítica se compreende o modo de pensar e fazer a educação tendo em vista problematizar as pedagogias tradicionais, admitindo-se que o conhecimento não é neutro, o que implica que atende aos vários fins em cada sociedade, reproduzindo e produzindo relações sociais. No que tange a essas implicações, pode-se destacar que a teoria educacional, ao incorporar em seu interior a "crítica", inicia a configuração de pressupostos marxistas, fenomenológicos e hermenêuticos que vêm ao encontro do diálogo para a construção de uma educação mais crítica, opondo-se às pedagogias tradicionais (LOUREIRO, 2006, p. 52-53).

Assim, essa corrente integrou o campo da educação à tendência da Pedagogia Progressista Histórico-Crítica, desenvolvida principalmente por Saviani, que buscou compreender a questão educacional a partir do desenvolvimento histórico, marcado por visão dialética e reflexão crítica e pela busca da transformação da sociedade, constituída por sujeitos em um processo histórico que engloba realidades multifacetadas (SAVIANI, 1991).

5 A Escola de Frankfurt foi criada por um grupo de intelectuais preocupados em compreender e desenvolver uma teoria crítica da sociedade. As figuras comumente associadas a essa escola são Horkheimer, Adorno, Marcuse, Fromm e Habermas. 
Com o compromisso básico de intervenção e transformação da sociedade, na vertente crítica, a corrente crítico-reflexiva ganha espaço no debate sobre a educação ambiental, bem como nos discursos dos profissionais educadores ambientais. Porém, ressalta-se que não é a única, mas uma das correntes presentes nesse debate.

A concepção de educação ambiental torna-se mais complexa, incorporando as dimensões sociais, culturais, políticas, econômicas e ecológicas, com enfoque no conhecimento e na compreensão das realidades e das problemáticas ambientais sob a visão da totalidade.

A partir desse olhar complexo sobre a realidade multifacetada, outras categorias vêm ao encontro dessa corrente, tais como: sustentabilidade, diálogo de saberes, complexidade, entre outras, conforme se nota nos fundamentos teórico-metodológicos da educação ambiental. Percebe-se, assim, que a educação ambiental transita por diversas fronteiras e, entre outras, aproxima-se de um possível desenho epistemológico.

Diante dessas abordagens, podem-se delimitar as diferentes maneiras de conceber e praticar a educação ambiental, sendo estas (re)construídas pelas experiências dos profissionais educadores ambientais, o que resulta em várias identidades socioambientais e políticas que se consolidam nos pensamentos e ações cotidianas.

Vale explicitar que nesse mosaico dos diversos territórios pelos quais a educação ambiental transita há uma disputa de significados e de interesses que se desenrola no ambiente interno do campo ambiental. É condicionada, por um lado, pelo exercício da crítica praticada pelos próprios educadores e, por outro lado, pelas influências do ambiente externo, formado pelas tendências político-econômicas dominantes na vida social que influencia o seu caminhar.

A partir desses (re)arranjos, a educação ambiental configura-se em diversas denominações que preenchem de sentido as práticas e as reflexões pedagógicas relacionadas à questão socioambiental.

Nesse estabelecimento das práticas, vai se construindo um contexto plural das educações ambientais: Ecopedagogia, Educação Ambiental Crítica, Educação Ambiental Transformadora, Educação no processo de Gestão Ambiental, Alfabetização Ecológica, Educação 
para as Sociedades Sustentáveis, Educação Ambiental Popular, Educação Ambiental Formal, entre outras.

Toma-se a posição aqui de que todas essas categorias emergem dos fundamentos básicos da educação ambiental, que são frutos das concepções que permeiam a educação ambiental, em um movimento antagônico e complementar que ora as torna solidárias, ora as distancia.

Portanto, não se pretende reduzir as múltiplas orientações a uma única educação ambiental, mas evidenciar que essas formulações sincrônicas encontram-se no debate do campo da educação ambiental.

\section{Considerações finais}

Acredita-se que a educação ambiental está construindo novas formas de pensar e agir diante das suas múltiplas correntes e da exploração das fronteiras internas do seu campo, na busca de novos paradigmas que emergem com um sentido de ruptura do pensamento reducionista e que vêm permeando as discussões do processo formativo da educação ambiental.

Para tal, é necessário, constantemente, (re)pensar e (re)avaliar essas identidades, fortalecendo toda a diversidade. E talvez seja diante dessa multiplicidade e pluralidade constituída que se possa aprender e compreender a complexidade e o saber ambiental, buscados na narrativa da educação ambiental, pois, diante desse contexto plural e espaços dinâmicos de diálogo entre as diferentes abordagens, faz-se possível uma decisiva contribuição nas bases de sustentação teórica e metodológica da educação ambiental.

Conforme Morin (1980), é necessária outra abordagem para que seja possível enxergar a complexidade da questão socioambiental. Uma abordagem que leve em conta o sujeito na construção do objeto, uma vez que, nos marcos do pensamento ocidental, sujeito e objeto, natureza e sociedade são termos que, ainda, se excluem. Nesse contexto, percebe-se que a educação ambiental tece caminhos que se aproximam de nova configuração teórica e metodológica.

Nesse devir, destaca-se que o processo formativo estabelecido pela educação ambiental nas fronteiras entre a modernidade e a pós- 
modernidade está se constituindo nas discussões e na problematização em torno de concepções mais solidárias ao diálogo de saberes que reflitam a relação sociedade-natureza e que busquem contribuir para a formação de sujeitos políticos, capazes de pensar e agir criticamente na sociedade, e a base desse processo são as vias de emancipação e transformação social.

\section{Referências}

BRASIL. Decreto-lei n. 9.795, de 27 de abril de 1999. Dispõe sobre a educação ambiental e institui a Política Nacional de Educação Ambienta e dá outras providências. Diário Oficial da União. Brasília, 1999.

BRUGGER, Paula. Educação on adestramento ambiental? Florianópolis: Letras Contemporâneas, 1994.

CARIDE, José Antonio. La educación ambiental: concepto, historia y perspectivas. In: __ (Coord.). Educación ambiental: realidades y perspectivas. Barcelona: Ariel, 1999.

CARVALHO, Isabel Cristina de Moura. A invenção ecológica: narrativas e trajetórias da Educação Ambiental no Brasil. Porto Alegre: UFRGS, 2001.

. Educação ambiental: a formação do sujeito ecológico. São Paulo: Cortez, 2004.

FREIRE, Paulo. Pedagogia da autonomia: saberes necessários à prática educativa. 2. ed. Rio de Janeiro: Paz e Terra, 1997.

GONZÁLEZ GAUDIANO, Édgar. Educación ambiental: historia y conceptos a veinte años de Tbilisi. México: SITESA, 1997.

GRÜN, Mauro. Ética e Educação ambiental: a conexão necessária. Campinas: Papirus, 1996.

GUIMARÃES, Mauro. Educaşão ambiental: no consenso um embate? Campinas: Papirus, 2000.

LEFF. Enrique. Saber ambiental: sustentabilidade, racionalidade, complexidade, poder. Tradução de Lúcia Mathilde Endlich Orth. Rio de Janeiro: Vozes, 2001.

LOUREIRO, Carlos Frederico B. Trajetórias e fundamentos da Educação ambiental. São Paulo: Cortez, 2004.

. Educação ambiental e teorias críticas. In: GUIMARÃES, Mauro. Caminhos da educaşão ambiental: da forma à ação. Campinas: Papirus, 2006. p. 51-86.

MEIRA, Pablo. Elogio da Educação ambiental: da década da Educação para o Desenvolvimento Sustentável ao Milênio da Educação ambiental. In: Jornadas 
Pedagógicas da Educação ambiental, 12.: Educação ambiental no contexto da década das Nações Unidas da Educação para o Desenvolvimento Sustentável (2005-2014). Ericeira. Anais... Ericeira: ASPEA, 2005, p. 14-18 [conferência].

MELLO, Lilian Medeiros de. A questão do formalismo no discurso oficial da educação ambiental. 83 f. Dissertação (Mestrado em Tecnologia) - Centro Federal de Educação Tecnológica, Curitiba, 2001.

MORALES, Angélica Góis . A formação do profissional educador ambiental: reflexões, possibilidades e constatações. Ponta Grossa: UEPG, 2009.

MORIN, Edgar. O método II: a vida da vida. 2. ed. Portugal: Publicações EuropaAmérica, 1980.

SATO, Michèle. Debatendo os desafios da educação ambiental. In: CONGRESSO DE EDUCAÇÃO AMBIENTAL PRÓ-MAR DE DENTRO, 1., 2001. Rio Grande. Anais... Rio Grande: FURG, 2001. p. 14-33.

SAUVÉ, Lucie. A Educação ambiental e Desenvolvimento Sustentável: uma análise complexa. Revista de Educação Pública, Cuiabá, v. 6, n. 10, p. 72-103, jul./dez. 1997. Disponível em: <http://www.ufmt.br/revista/>. Acesso em: nov. 2005.

SAVIANI, Dermeval. Educação e questões da atualidade. São Paulo: Cortez, 1991.

SUREDA, Jaume; COLOM, Antoni. Pedagogía ambiental. Barcelona: CEAC, 1989.

TOZONI-REIS, Marília Freitas de Campos. Educação ambiental: natureza, razão e história. Campinas: Autores Associados, 2004.

TRISTÃO, Martha. A educação ambiental na formação de professores: redes de saberes. São Paulo: Annablume, 2004.

Artigo: recebido em 11/05/2009 - aprovado em 27/11/2009 